\title{
USEtox characterisation factors for textile chemicals based on a transparent data source selection strategy
}

\author{
Sandra Roos ${ }^{1,2}$ (D) $\cdot$ Hanna Holmquist ${ }^{1} \cdot$ Christina Jönsson $^{2} \cdot$ Rickard Arvidsson $^{1}$
}

Received: 13 December 2016 / Accepted: 1 May 2017 / Published online: 1 June 2017

(C) The Author(s) 2017. This article is an open access publication

\begin{abstract}
Purpose Life cycle assessments (LCAs) of textile products which do not include the use and emission of textile chemicals, such as dyes, softeners and water-repellent agents, will give non-comprehensive results for the toxicity impact potential. The purpose of this paper is twofold: (1) to provide a set of characterisation factors $(\mathrm{CFs})$ for some of the most common textile chemicals and (2) to propose a data source selection strategy in order to increase transparency when calculating new CFs.

Methods A set of 72 common textile-related substances was matched with the USEtox 2.01, USEtox 1.01 and the COSMEDE databases in order to investigate coverage and coherence. For the 25 chemicals that did not already have established CFs in any of these databases, new CFs were calculated. A data source selection strategy was developed and followed in order to ensure consistency and transparency, and USEtox 2.01 was used for calculations. The parameters that caused the most uncertainty were identified during the modelling and strategies for handling them were developed. Results and discussion Of the 72 textile-related substances, 48 already had calculated recommended or indicative CFs in existing databases, which showed good coherence. The main
\end{abstract}

Responsible editor: Serenella Sala

Electronic supplementary material The online version of this article (doi:10.1007/s11367-017-1330-y) contains supplementary material, which is available to authorized users.

Sandra Roos

sandra.roos@swerea.se

1 Division of Environmental Systems Analysis, Chalmers University of Technology, Rännvägen 6, 41296 Gothenburg, Sweden

2 Swerea IVF, PO Box 104, 43122 Mölndal, Sweden uncertainty identified during the calculation of 25 new CFs was the selection of input data regarding toxicity and degradation in water. However, for substances such as per- and polyfluoroalkyl substances (PFAS), the acid dissociation constant $\left(\mathrm{pK}_{\mathrm{a}}\right)$ and partitioning coefficients $\left(K_{\mathrm{ow}}\right.$ and $\left.\mathrm{K}_{\mathrm{OC}}\right)$ also require special considerations. Other input parameters had less than one order of magnitude impact on the CF result for essentially all substances.

Conclusions The paper presents a strategy for how to provide a complete set of toxicity CFs for a given list of substances. In addition, such a set of CFs for common textile-related substances is presented. The data source selection strategy provides a structured and transparent way of calculating additional CFs for textile chemicals with USEtox. Consequently, this study can help future LCA studies to provide relevant guidance towards environmentally benign chemical management in the textile industry.

Keywords Life cycle assessment(LCA) - Textile · Chemical · USEtox $\cdot$ Characterisation factor $\cdot$ Toxicity

\section{Introduction}

When performing life cycle assessment (LCA), the importance of including potential toxicity impacts of chemicals has been highlighted in several studies (Larsen et al. 2009; Laurent et al. 2012; Panko and Hitchcock 2011). For textile products in particular, the constantly ongoing emissions of toxic chemicals in textile production, including dyes, softeners and water-repellent agents, are an environmental problem of high relevance (European Commission 2003). Thus, emissions of toxic chemicals from textile production should be a highly relevant environmental aspect to include in LCA studies of textile products. There are, however, shortcomings in 
toxicity impact assessment methods that hinder such an inclusion. One shortcoming is the lack of characterisation factors (CFs) for textile chemicals. This is crucial, since it is the CF that relates the emission $(E)$ of a substance $(i)$ in the life cycle inventory (LCI) to potential environmental impacts $(I)$ according to the following relationship (Pennington et al. 2004):

$I=\sum_{i} C F_{i} \times E_{i}$

A recent literature review of LCA studies of textile products showed that textile chemicals were included in the LCI in only 7 out of 58 published studies (Roos 2015). In addition, in three of these seven studies, no matching with CFs to assess potential toxicity impacts of the textile chemicals was done. Thus, in 54 out of 58 relevant studies, the potential toxicity impact of textile chemicals was not included in the reported toxicity impact potential of the product. In addition, it was found that the exclusion of textile chemicals in these 54 studies was made tacitly, which means that the exclusion is not explicitly stated to the reader (Roos 2015).

LCA is also used to assess impact from textile products as commissions for the textile industry. To the authors' knowledge, such studies that are not published in scientific journals and databases do not include potential toxicity impacts either. As a result of this situation, LCA studies of textile products often report incomprehensive potential toxicity impact results.

In this paper, we seek to amend this situation. Our purpose is twofold: (1) to provide a set of CFs for some of the most common textile chemicals and (2) to propose a data source selection strategy for experimental and estimated data in order to increase transparency when calculating new CFs. The overarching purpose is to facilitate calculation and application of CFs of textile chemicals in the future and ensure that LCA results can provide relevant guidance for the academic community as well as the textile industry towards an environmentally benign chemicals management in the textile industry.

\section{Methods}

The USEtox model (Rosenbaum et al. 2008) was used to calculate human toxicity and freshwater ecotoxicity impacts of textile chemicals in an explorative case study. In USEtox, a human toxicity characterisation factor for a substance is derived from the product of three matrices including fate factors $(F F)$, human exposure factors $(X F)$ and human toxicological effect factors $(E F)$ :

$$
C F=E F X F F F
$$

An ecotoxicological characterisation factor for freshwater ecosystems for a substance is likewise derived from the product of fate factors (FF), freshwater ecosystem exposure factors
(XF) and freshwater aquatic ecosystem toxicity effect factors (EF) (Huijbregts et al. 2015b). USEtox is a consensus model for toxicity impact assessment in LCA, endorsed by the UNEP/SETAC Life Cycle Initiative (Westh et al. 2015). It contains a global, nested multi-media box model of the transport and fate of contaminants. It is recommended by the International Reference Life Cycle Data (ILCD) handbook (European Commission 2011), the Product Environmental Footprint (PEF) initiative (European Commission 2013) and the United States Environmental Protection Agency (Bare 2012). The USEtox database provides pre-calculated CFs for over 3000 substances, which reflects the availability of data for substances at the time of development. The USEtox model is available as an open-source tool for calculation of additional CFs. However, the REACH pre-register database (ECHA 2008) contains over 145,000 unique substances, so the precalculated CFs cover only a limited share of all existing chemicals. Only in the textile industry, the number of chemicals in use exceeds 15,000 (>10,000 colourants (SDC and AATCC 2016) and >5000 auxiliaries (TEGEWA 2016)).

\subsection{Evaluation of coverage and coherence of CF databases}

For this case study, a set of 72 textile-related substances was retrieved from the inventories of two previous studies of textile products (Holmquist et al. 2016; Roos et al. 2015), listed in Table S1 (Electronic Supplementary Material). The substances are of relevance since they are (1) used in commonly occurring textile processes, and/or (2) emitted to the environment from textile processes, and/or (3) emitted during the textile's use phase or end of life and/or (4) formed during environmental degradation processes of previously mentioned substances.

An evaluation was made of the coverage of the textile relevant substances in different $\mathrm{CF}$ databases based on different versions of USEtox: (1) the database provided with the most current version of USEtox (2.01), (2) the database provided with an older version (USEtox 1.01) and (3) the COSMEDE database (ADEME 2015). COSMEDE is a database with CFs and background data for the calculation of CFs applied to cosmetic and detergent substances. COSMEDE claims to use USEtox 1.01 for the calculation of CFs, which are based on input data that might differ from the data used in USEtox (Maillard et al. 2013). The coherence between the three databases with regard to CFs for the set of 72 textilerelated substances was also investigated.

\subsection{Strategy development}

A data source selection strategy was developed to complement the USEtox manual (Huijbregts et al. 2015b) and the principles outlined in the manuals of the USEtox databases (Huijbregts et al. 2015a, c). This strategy was based on the use of publicly 
available data in a transparent and scientifically sound manner, aiming for consistence with the existing USEtox CFs and at the same time covering as many substances as possible. The data source selection strategy was developed during the data collection for the 25 textile-related chemicals for which CFs were to be calculated within the scope of this study. The strategy is presented in this paper's methods section and the details of the data collection for the 25 substances are presented in the Supplementary material (S3).

\subsubsection{Best-estimate approach for data}

The selection of input data to an LCA study is dependent on the aim of the study as well as the intended use of the CFs, and is therefore dependent on the situation and decision context (European Commission 2010). The USEtox approach is to calculate CFs for comparative purposes (Rosenbaum et al. 2008) and thus, generally, apply an average or "best-estimate" approach. For instance, for the freshwater ecotoxicity effect factor, the input to the USEtox model is the chronic hazard concentration obtained from the arithmetic mean of the logarithmised geometric means of species-specific chronic effect concentrations $\left(\mathrm{EC}_{50}\right)$ (Huijbregts et al. 2015c). Additionally, in an LCA study containing several substances in the inventory, there is not only one type of non-cancer human toxicity effects covered. For example, the CF can reflect severe chronic damage to foetus development as well as temporary skin irritation (Rosenbaum et al. 2011). For cancer human toxicity effects, the CF can likewise reflect different cancer causes including both substances that induce tumours and that increase their incidence. In the present study, use of the best-estimate approach was continued in order to allow for the use of the CFs in a traditional LCA context where different products and/or services are compared and to provide consistency with pre-calculated USEtox CFs. This choice is in line with the original purpose of USEtox, and provides consistency with pre-calculated USEtox CFs.

\subsubsection{Evaluation of data sources for inclusion in the strategy}

Data on physicochemical properties, bioaccumulation and toxicity of substances are available via a number of sources. In the first stage of strategy development, available data sources were identified, whereafter all data relevant for the USEtox input parameters were retrieved. The second stage included data quality evaluation and prioritisation. In order to enable transparency to the method, it was differentiated between experimental and estimated data.

Experimental data were retrieved from open (noncommercial) data sources (listed in Table 1). The search was limited to data sources that (1) contained experimental data, (2) could be searched for CAS numbers and (3) were accessible via the Internet. In addition, peer-reviewed scientific journals (via Scopus; www.scopus.com) were scanned for papers reporting experimental data. During the identification of data sources, no differentiation between standard and nonstandard testing (e.g. by validated OECD testing guidelines) was made, neither was accordance with good laboratory practice (GLP). These aspects were assessed in the subsequent evaluation.

The USEtox manual (Huijbregts et al. 2015b) gives explicit guidance regarding the use of estimated data to calculate the fate factor. The manual opens up for the use of estimated data, but gives no further guidance, for the ecotoxicological effect factor and clearly states that experimental data should be used for calculation of the human health effect factors. Given the necessity to fill as many data gaps as possible for relevant application of toxicity in LCIA, we propose to include estimated data as input when experimental data are missing for fate and exposure factors as well as for effect factors. This deviation from the USEtox manual is justifiable in the light of current development where estimated data are increasingly being used to fill data gaps, e.g. in regulatory contexts (European Commission 2006; Swedish Chemicals Agency 2017).

For generation of estimated data, established methods are available via open (non-commercial) sources. Estimation methods enable the filling of data gaps by using experimental data from structurally similar substances in a quantitative structure activity relationship (QSAR) and/or category/grouping approach (see, e.g. Cronin and Madden (2010), ECHA (2014) and OECD (2014)). As part of the strategy development, available estimation methods to fill the toxicity data gaps were inventoried and evaluated for the purpose, aiming for a method that can be used by general LCA experts (detailed description in the Supplementary material (S4)). This meant that the method should be easily accessed, possible to use without prior QSAR expertise and admit as many substances as possible within the valid domain, whilst at the same time generate as robust and reliable results as possible. In contrast to the data source selection for databases, only one model per endpoint was selected for toxicity data estimation, as it would be out of scope, given the novelty of the approach and the scope of this paper, to extend this part further. The models selected were ECOSAR (US EPA 2012) for ecotoxicity and QSAR Toolbox (OECD 2016a) for mammalian toxicity. To fill as many data gaps as possible, the acuteto-chronic extrapolation, as suggested by Rosenbaum et al. (2011), was used as a complementary method to estimate cancer (if indicated to be mutagenic) and non-cancer $\mathrm{ED}_{50}$ based on acute $\mathrm{LC}_{50}$ values as predicted with the US EPA T.E.S.T. model (US EPA 2017).

\subsubsection{Data quality assessment}

Minimum data quality (MDQ) criteria for data collection were established to aid the data selection. The data quality was 
Table 1 Data sources used for data collection in this study, in priority order

\begin{tabular}{|c|c|c|}
\hline Priority order & Data source & Reference \\
\hline \multicolumn{3}{|c|}{ Environmental fate and exposure data } \\
\hline 1 & EPI Suite, experimental data ${ }^{c}$ & USEPA (2007) \\
\hline 2 & USEtox internal estimation routines ${ }^{\mathrm{c}}$ & Huijbregts et al. (2015b) \\
\hline 3 & EPI Suite, estimated data ${ }^{c}$ & USEPA (2007) \\
\hline 4 & $\begin{array}{l}\text { Other (e.g. databases searchable via OECD eChemPortal and } \\
\text { databases of peer-reviewed literature) }\end{array}$ & \\
\hline \multicolumn{3}{|c|}{ Ecotoxicological effect data } \\
\hline 1 & ECOTOX $^{\mathrm{c}}$ & USEPA (2000) \\
\hline 2 & OECD SIDS IUCLID ${ }^{\mathrm{a}, \mathrm{c}}$ & IUCLID (2007) \\
\hline 3 & ECHA CHEM $^{\mathrm{a}, \mathrm{d}}$ (REACH registration data) & ECHA (2008b) \\
\hline 4 & EFSA Open Food Tox ${ }^{\mathrm{a}}$ & EFSA (2016) \\
\hline 5 & $\begin{array}{l}\text { ECHA C\&L Inventory }{ }^{\mathrm{a}} \text { (harmonised classification gives a } \\
\text { property interval) }\end{array}$ & ECHA (2013) \\
\hline 6 & $\begin{array}{l}\text { Other (e.g. PPDB, PubChem, databases of peer-reviewed } \\
\text { literature) }\end{array}$ & \\
\hline 7 & Data estimation methods (ECOSAR) & US EPA (2012) \\
\hline \multicolumn{3}{|c|}{ Human toxicological effect data } \\
\hline 1 & US EPA IRIS ${ }^{\mathrm{b}, \mathrm{c}}$ & US EPA (1985) \\
\hline 2 & $\operatorname{HSDB}^{\mathrm{a}, \mathrm{b}, \mathrm{c}}$ & NLM (2011) \\
\hline 3 & OECD SIDS IUCLID ${ }^{\mathrm{a}, \mathrm{c}}$ & IUCLID (2007) \\
\hline 4 & ECHA CHEM $^{\mathrm{a}, \mathrm{d}}$ (REACH registration data) & ECHA (2008b) \\
\hline 5 & EFSA Open Food Tox ${ }^{\mathrm{a}}$ & EFSA (2016) \\
\hline 6 & $\begin{array}{l}\text { ECHA C\&L Inventory }{ }^{\mathrm{a}} \text { (harmonised classification gives a } \\
\text { property interval) }\end{array}$ & ECHA (2013) \\
\hline 7 & $\begin{array}{l}\text { Other (e.g. PPDB, PubChem, databases of peer-reviewed } \\
\text { literature) }\end{array}$ & \\
\hline 8 & Data estimation methods (QSAR Toolbox) & OECD (2016b) \\
\hline
\end{tabular}

${ }^{a}$ These databases are available via the eChemPortal (OECD 2016a). The eChemPortal connects several highquality databases, and substance properties can be searched directly at the portal from four databases: CCR (OECD 2014b), ECHA CHEM (ECHA 2008b), J-CHECK (NITE 2010) and OECD SIDS IUCLID (IUCLID 2007)

${ }^{\mathrm{b}}$ These databases are available via TOXNET (NLM 2005). TOXNET is a web portal that connects high-quality toxicology databases such as IRIS (US EPA 1985) and HSDB (NLM 2011)

${ }^{\mathrm{c}}$ Databases prioritised in the USEtox manual. HSDB was used in Rosenbaum et al. (2011) and therefore considered prioritised

${ }^{\mathrm{d}}$ Data from the REACH registration database is subject to copyright laws and may require the permission of the owner of the information

classified into categories A-F (Table 1). The proposed criteria for MDQ for experimental data (step II) are based on the principles behind the Klimisch scoring system (Klimisch et al. 1997).

\subsection{Proposed data source selection strategy}

The data source selection strategy proposed in the present study includes three steps, presented in Fig. 1. The goal of the strategy is to retrieve complete data sets in order to calculate CFs for as many substances as possible. The goal is to further transparently communicate uncertainties to allow for their consideration in the LCA interpretation. Step I is to search for data in the USEtox-endorsed databases, i.e. those listed in the USEtox manuals (Huijbregts et al. 2015a, b, c), giving priority to the user manual. If a complete data set (aquatic ecotoxicity data covering three trophic levels and/or human health cancer and/or non-cancer effects, depending on the goal of the study) of MDQ is achieved in this step, the data search is done. See Supplementary material (S2) for a description of the data requirements in the USEtox model. In step II, experimental data is retrieved from other data sources that can provide MDQ, primarily those in eChemPortal (OECD 2016b), further detailed in Table 1. Again, if this step renders a complete data set ofMDQ, the search is over. In step III, for parameters where experimental data of MDQ were not available, a weight-of-evidence (WoE) approach was used (as a method to include all evidence, see, e.g. Weed (2005)), combining estimated data from the application of QSAR or other estimation methods with experimental data from step II. CFs based on estimated data cannot reach MDQ unless supported by some experimental data. The assessment of MDQ in the third step was made on a case-by-case basis. The estimated data 


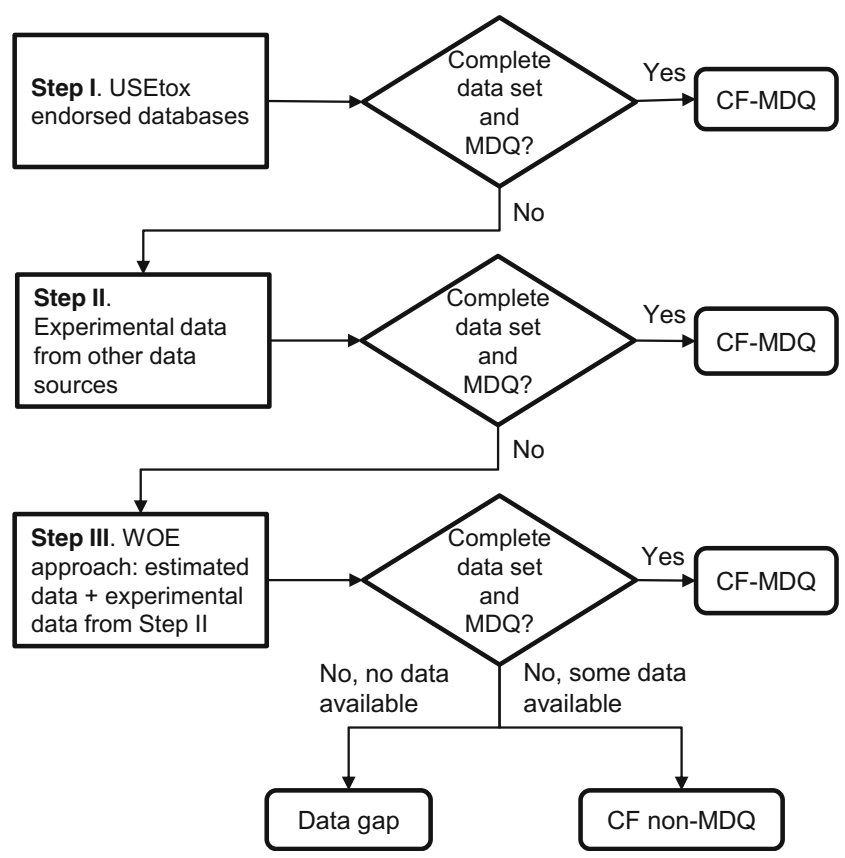

Fig. 1 The three-step data source selection strategy developed for the study. WOE weight of evidence, $M D Q$ minimum data quality, $C F$ characterisation factor

had to fulfil the criteria as defined in Table 1, and the non-MDQ experimental data had to point in the same direction (cf. WoE approach in REACH Annex XI). One example is the DyestuffE (CAS no.149850-30-6) for which experimental data corresponded well with the ECOSAR estimated data. A detailed description of the methodological procedure for data estimation is included in section S4 in the Supplementary material. This description can be used as guidance for the user of the proposed data source selection strategy.

\subsubsection{Priority order for data sources}

Based on the MDQ criteria (Table 2) and the data source selection strategy (Fig. 1), a priority order for search in databases was created (Table 1). The databases endorsed by USEtox have the highest priority, followed by databases found to be able to provide MDQ and had a wide coverage of substances.

Priority order means that when sufficient data of MDQ is found in a database, the databases with lower priority are not searched. For example, for ecotoxicity data in terms of $\mathrm{EC}_{50}$, data from three trophic levels (normally algae, invertebrates and fish) are required to calculate the effect factor in USEtox (Rosenbaum et al. 2008). If three trophic levels could be covered with MDQ data after search in the ECOTOX database (USEPA 2000), which has priority order 1 , then the data search was stopped. This pragmatic strategy is intended to provide transparency, since the user of the CF can then know from which sources the data originate. A similarly pragmatic approach was applied to the data estimation (part of step III), where publicly available estimation methods (QSAR models and grouping methods) were selected based on criteria of availability, user-friendliness and documentation of scientific soundness. The data source selection was made within the present context, and consequently, the priority order of data sources in Table 1 is dominated by European data sources. A practitioner doing a case study in a different context could make a different priority order. The motivation for the priority order and selection of data estimation methods is described in detail in the Electronic Supplementary Material (S3).

\subsection{Calculation of new CFs}

For the 25 textile-related substances not covered in any of the three CF databases, new CFs were calculated with USEtox 2.01, using data collected following the recommendations for data selection and data treatment in the USEtox ${ }^{\mathrm{TM}}$ user manual (Huijbregts et al. 2015b) and the data source selection strategy as presented above.

\subsection{Sensitivity analysis}

\subsubsection{Simplified sensitivity analysis of the dependency on input parameters}

A simplified sensitivity analysis was performed where the generic dependency on input parameters and the data source selection strategy for the CF results was investigated. All input parameters to the USEtox model were increased and decreased by two orders of magnitude.

\subsubsection{CF dependency on data source selection}

For a specific substance group (per- and polyfluoroalkyl substances (PFAS)), special considerations may be needed in fate modelling due to their environmental partitioning behaviour and the difficulty to accurately define physical-chemical property values (Armitage 2009; Armitage et al. 2006). Fate parameters such as, e.g. partitioning coefficients, are difficult to determine experimentally (Armitage 2009), and EPIsuite-estimated physical-chemical data may be associated with extra uncertainty for the PFAS, as indicated by a study where Wang et al. (2011) could show that EPIsuite performed less well in a comparative study of models to predict physicochemical properties of PFAS. To explore the implications of this special challenge posed by the PFAS, the EPIsuite data were complemented by experimental data retrieved from literature for three PFAS, namely 4:2 fluorotelomer alcohol (4:2 FTOH), perfluorohexanoic acid (PFHxA) and perfluorooctanoic acid (PFOA). The physicochemical parameters included were solubility (Sol 25), vapour pressure (Pvap25), the octanol-water partitioning coefficient $\left(K_{\text {ow }}\right)$, Henry's law constant $(\mathrm{KH} 25 \mathrm{C})$ and $\mathrm{pK}_{\mathrm{a}}$. To investigate the influence of the data source selection, a sensitivity analysis 
Table 2 Criteria and categorisation for data quality assessment

\begin{tabular}{|c|c|c|}
\hline Data quality category & Comment & MDQ \\
\hline \multicolumn{3}{|l|}{ Step I } \\
\hline A & $\begin{array}{l}\text { Data collected according to the process outlined in the USEtox } \\
\text { manuals are automatically considered MDQ since the CFs } \\
\text { are aimed to be as similar as the USEtox } \\
\text { CFs as possible }\end{array}$ & Yes \\
\hline \multicolumn{3}{|c|}{ (6) } \\
\hline $\mathrm{B}$ & $\begin{array}{l}\text { Data ranked as Klimisch score } 1 \text { and } 2 \text { (including industry } \\
\text { self-ranking), i.e. a well-performed study with complete } \\
\text { documentation }\end{array}$ & Yes \\
\hline $\mathrm{C}$ & $\begin{array}{l}\text { Data peer-reviewed by a reliable third party (e.g. from articles } \\
\text { in peer-reviewed scientific journals or reports published by } \\
\text { an authority or other competent body), which is believed } \\
\text { to use assessment criteria equivalent to Klimisch scores } 1 \text { and } 2\end{array}$ & Yes \\
\hline $\mathrm{D}$ & $\begin{array}{l}\text { Data ranked as Klimisch score } 3 \text { and } 4 \text { (including industry } \\
\text { self-ranking), i.e. a study not relevant for the purpose and/or } \\
\text { of low quality or lacking complete documentation }\end{array}$ & No \\
\hline \multicolumn{3}{|l|}{ Step III } \\
\hline E & $\begin{array}{l}\text { Data calculated with an estimation method relevant for the } \\
\text { chemical structure; e.g. the substance is within the application } \\
\text { domain for the (Q)SAR-model, and based on a robust/reliable } \\
\text { grouping/categorisation and /or (Q)SAR, and is supported by } \\
\text { some experimental data }\end{array}$ & Yes $^{\mathrm{a}}$ \\
\hline $\mathrm{F}$ & $\begin{array}{l}\text { Data calculated for a substance outside the application domain } \\
\text { of the }(\mathrm{Q}) \mathrm{SAR} \text { or by a grouping/categorisation and/or }(\mathrm{Q}) \mathrm{SAR} \\
\text { that is not reliable/robust, or is not supported by any } \\
\text { experimental data }\end{array}$ & $\mathrm{No}^{\mathrm{a}}$ \\
\hline \multicolumn{3}{|c|}{$W O E$ weight of evidence, $M D Q$ minimum data quality, $C F$ characterisation factor } \\
\hline \multicolumn{3}{|c|}{$\begin{array}{l}{ }^{a} \text { Estimated data (data quality categories } \mathrm{E} \text { and } \mathrm{F} \text { ) are used together with experimental data from step II in a } \\
\text { weight-of-evidence approach when sufficient experimental data to arrive at CF-MDQ are not available, i.e. if } \\
\text { available data are of low quality (data quality category D) or do not cover all relevant species/endpoints (data } \\
\text { quality B and C) (see Fig. 1) }\end{array}$} \\
\hline
\end{tabular}

was performed using data for the same input parameter from different data sources.

\section{Results and discussion}

This section reports the investigation of the coverage and coherence of existing USEtox-based databases for the textilerelated substances, the $25 \mathrm{CFs}$ that were calculated and the evaluation of the CFs' dependency on input parameters and the data source selection strategy.

\subsection{Coverage and coherence of existing databases}

Of the 72 examined substances, the COSMEDE database was found to have the greatest coverage of CFs (47 substances) compared with those for USEtox 2.01 (22 substances) and USEtox 1.01 (21 substances). It should be noted that the COSMEDE CFs generally do not cover human toxicity, but mainly ecotoxicity. The respective mid-point CFs for emissions to freshwater (most relevant for textile industry) are shown in Table S4 (Electronic Supplementary Material), where it can be seen how the CFs vary between the different databases for all the substances. Regarding the different results for CFs in USEtox 1.01 compared with USEtox 2.01, this can be explained by differences in the model. The differences between the existing CFs from USEtox 1.01 and COSMEDE more likely come from differences in input data, since COSMEDE claims to be based on the USEtox 1.01 model.

Only for one chemical (octamethyltetrasiloxane, a common precursor to silicon-based chemicals) did the CFs vary more than one order of magnitude between databases. Thus, the COSMEDE database seems not to have become obsolete after the update to USEtox 2.0 model, since the difference was moderate for this set of substances. For one chemical (Dyestuff A), COSMEDE provided a CF for ecotoxicity, whilst USEtox 1.01 and 2.01 did not. This suggests that developers of the USEtox 1.01 and 2.01 used sources where the substance's ecotoxicity was either not documented, or the data quality was deemed insufficient. 


\subsection{New CFs for 25 textile-related substances}

The results from the calculations of new CFs, using the data source selection strategy from Fig. 1, are shown in Table 3 together with the main sources of uncertainty in the modelling. All CFs are for emissions of textile-related chemicals to the continental freshwater compartment. Table S2 (Electronic Supplementary Material) contains the collected input data for running the USEtox 2.01 model for the 25 textile-related substances. CFs for emissions to other compartments than continental freshwater are shown in Table S3 (Electronic Supplementary Material). All CFs should be regarded as indicative, and if they are going to be used for more than screening purposes, they should be further verified.

An interesting observation was that one surfactant, the alpha-MES, is marketed as "environmentally friendly" under CAS RN 93348-22-2 (e.g. Henan Surface Industry Co Ltd. 2016), but is also documented to be structurally very similar to a known toxic surfactant (CAS RN 4016-24-4 (OECD SIDS 2003)). The CF for alpha-MES was shown to be relatively high for all compartments compared with the other substances in the data set. Therefore, it is recommended to include all substances when calculating CFs, regardless of market claims.

\subsubsection{Implications of the inclusion of estimated data}

The inclusion of data estimation methods as part of the data collection strategy allowed for calculation of CFs for 15 additional substances. This is an important addition since those substances would without a CF be assessed as having no toxicity impact in the LCA. However, the inclusion of estimated data also brought with it a number of challenges. Despite the careful model selection, it was difficult to achieve robust and reliable results due to three main reasons: (i) the difficulty to assess the precision and accuracy of the estimated data, especially since many of the substances in the data set have complex chemical structures; (ii) the complex work flow of the read-across methods in the QSAR Toolbox, making them time consuming and limiting reproducibility of the results as the uncertainty in the estimated data is directly linked to the analyst's knowledge, experience and skills, in particular related to the category building (Dimitrov et al. 2016); and (iii) in the case of the human health non-cancer endpoint, the complexity of the endpoint. These challenges were addressed in the final model selection (see Electronic Supplementary Material (S4)), where the QSAR Toolbox read-across approach was abandoned and (Q)SAR models were selected instead. For the human health non-cancer effects, the heterogenic endpoint (non-cancer effects from repeated dose toxicity can be many) made it difficult to find one (Q)SAR model and all estimated data were based on the acute-to-chronic extrapolation (Rosenbaum et al. 2011). A few substances could not be modelled since they were outside the model domain, and in such cases, as an additional complement, default factors could be developed based on data in the existing databases but this was not applied in the present study. The advantage with default factors is that each substance will render a result in the LCIA calculation, and thus, emission volumes and exposure can still be considered.

\subsection{Results from the sensitivity analysis}

\subsubsection{Generic CF dependency on input parameters}

The data selection is one important contributor to input parameter uncertainty when CFs are calculated. Previous studies have shown that for emissions to freshwater, it is in general the toxicity parameters (i.e. $\mathrm{EC}_{50}$ values) that have the largest influence on freshwater ecotoxicity in USEtox (Alfonsín et al. 2014; Igos et al. 2014). Other parameters might be important too, depending on toxicity pathways and effects (Hauschild et al. 2011).

In the sensitivity analysis, the generic dependency on input parameters for the $\mathrm{CF}$ results was investigated for the 25 textilerelated chemicals for which new CFs were calculated. All input parameters to the USEtox model were increased and decreased two orders of magnitude. It must be pointed out that many of these parameter values are not possible to find in real-life measurements; thus, this sensitivity analysis is only theoretical with the purpose of exploring which input parameters are most sensitive for different types of chemicals. The input parameters to which the CFs are most sensitive can be examined in greater detail in the subsequent iterations of a study, whilst less scrutiny is needed for the other parameters. For these less sensitive parameters, default values could even be used.

Table 4 summarises the main findings of the sensitivity analysis, and Fig. 2 shows the sensitivity analysis results for freshwater ecotoxicity $\mathrm{CFs}$ for emissions to freshwater for the input parameters $K_{\mathrm{ow}}, \mathrm{k}_{\mathrm{degW}}$ and avlogEC $\mathrm{C}_{50}$. The full sensitivity analysis results are shown in Figs. S1, S2, S3 and S4 (Electronic Supplementary Material). The toxicity impact parameters (avlogEC $50\left(\log \mathrm{HC}_{50}\right)$ and $\mathrm{ED}_{50}$, respectively) were very important for all emission compartments and impact categories. The value of the input parameters for the degradation rate in water $\left(\mathrm{k}_{\mathrm{deg} W}\right)$ was shown to be the second most important parameter; only for effects on human toxicity from emissions to urban air did this parameter have an insignificant influence. For effects on human toxicity from emissions to water, the bioaccumulation factor in fish/biota (BAFfish) was important too. Other input parameters had less than one order of magnitude impact on the CF result for essentially all substances, with a few exceptions, further described in section S5 in the Supplementary material.

Since the CFs are not heavily dependent on the physicochemical data, but rather on toxicity parameters, this suggests that it is of less importance to add further data sources 


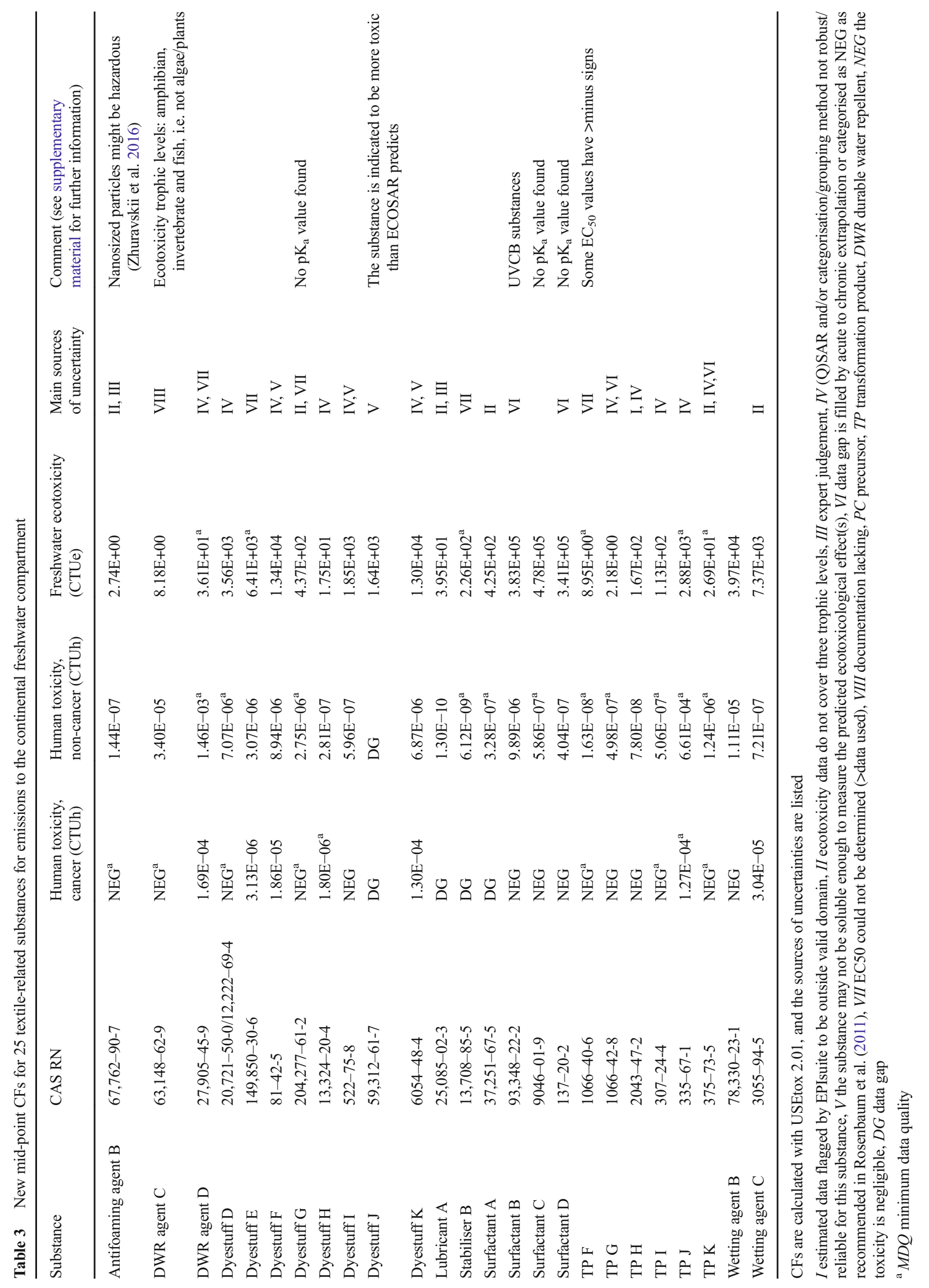


Table 4 Sensitivity to input parameters to the USEtox model for the selected data set per emission compartment and impact category

\begin{tabular}{lll}
\hline & Freshwater ecotoxicity & Human toxicity \\
\hline Emissions to urban air & avlog EC50 & ED50 \\
& $k_{\operatorname{degW}}$ & \\
Emissions to freshwater & avlog EC50 & ED50 \\
& $k_{\operatorname{degW}}$ & $k_{\operatorname{deg} W}$ \\
& & BAF \\
\hline
\end{tabular}

Parameters affecting the $\mathrm{CF}$ with more than a factor of 10 and that affected more than $25 \%$ of the substances are considered of main importance and included in the table regarding physiochemical data to the data source selection strategy (Table 1) at this stage. Table 1 is focused on the toxicity input data in the form of $\mathrm{EC}_{50}$ and $\mathrm{ED}_{50}$ values, which can indeed vary with several orders of magnitude between substances in reality. In addition, toxicity data was shown to be the most difficult data to retrieve. This is therefore the most important input parameter to put effort in acquiring in a consistent and transparent manner during the data selection. It is important to remember that even when high-quality experimental data for cancer and non-cancer toxicity do exist, the extrapolation of toxicity data of chemical compounds from
Fig. 2 CF sensitivity to selected input parameter values $\left(K_{\mathrm{ow}}\right.$, $k_{\mathrm{degW}}$ and $\left.\operatorname{avlog} \mathrm{EC}_{50}\right)$. Freshwater ecotoxicity $\mathrm{CF}$ for emissions to continental freshwater. All numbers normalised against base case CF from 3.2. TP transformation product, $D W R$ durable water repellent
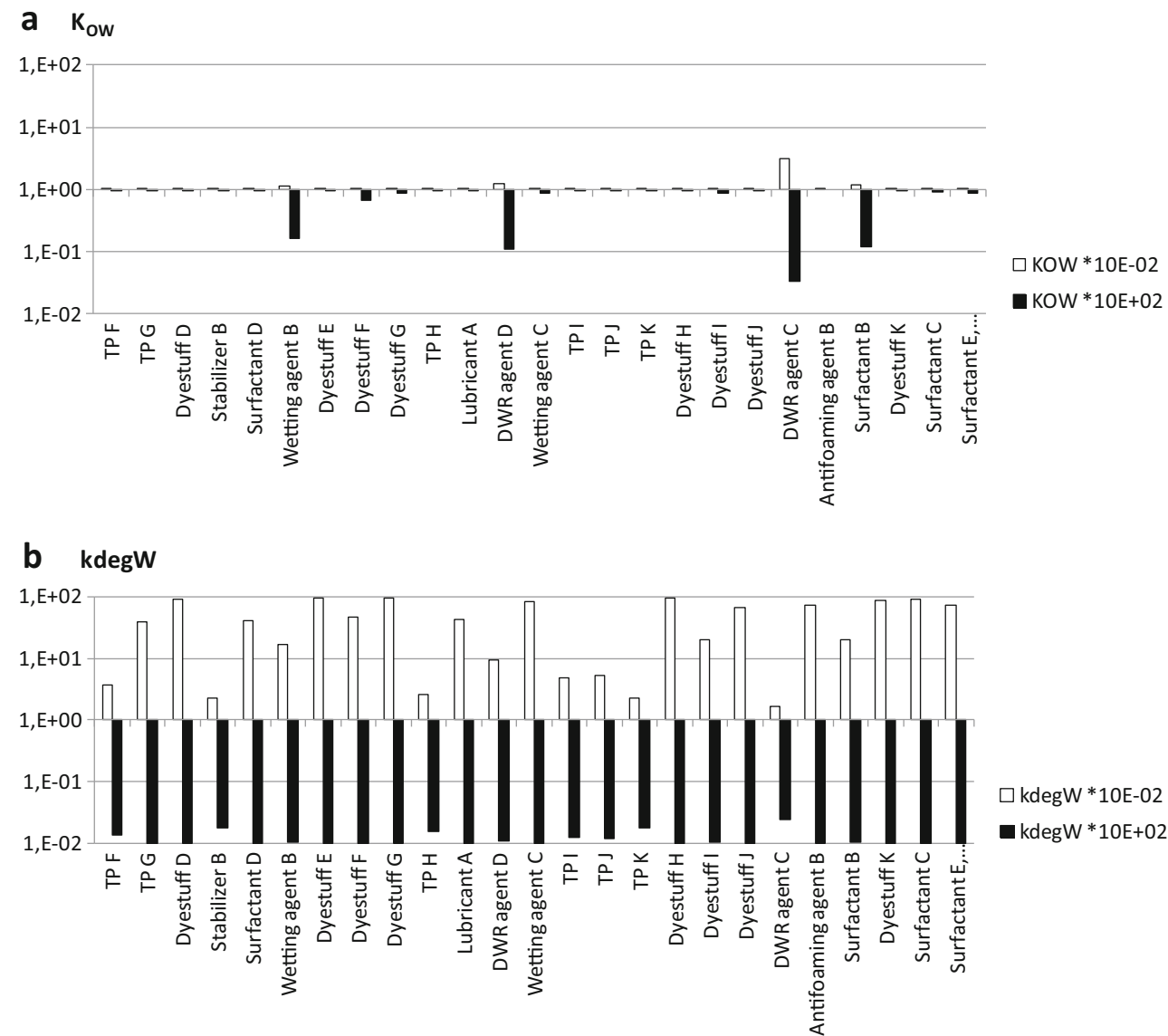

\section{C avlogEC50}

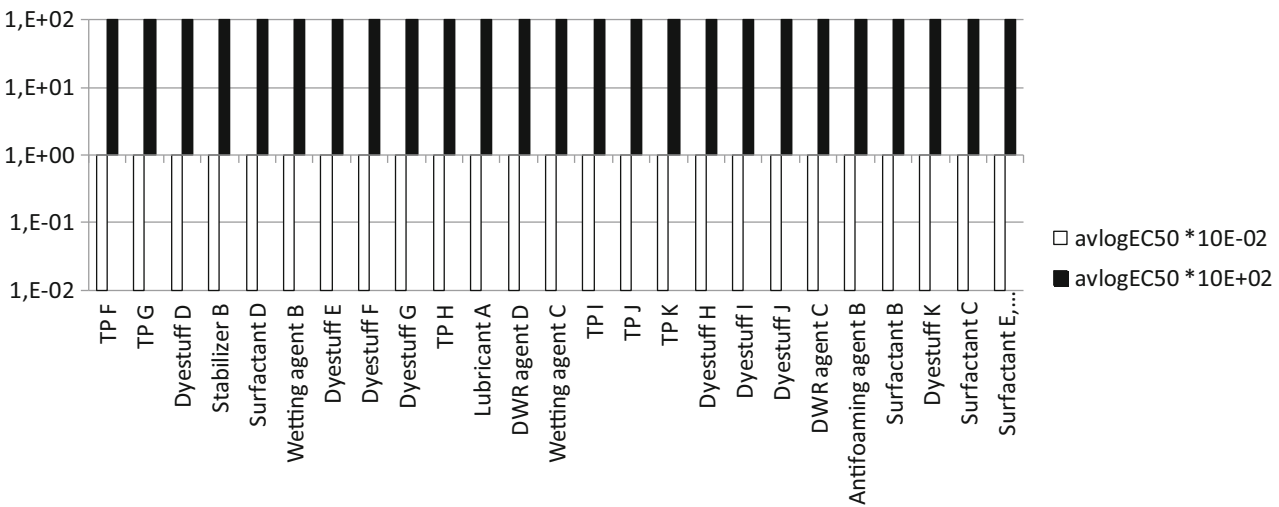


mammalian species to humans, using interspecies factors, adds uncertainty. One group of substances that stand out in the sensitivity analysis is the fluorinated acids, which was shown to be relatively sensitive to the acid dissociation constant $\left(\mathrm{pK}_{\mathrm{a}}\right)$. This is in contrast to most other substances, which were generally only sensitive to toxicity parameters (Figs. S1-S4).

\subsubsection{PFAS CF dependency on data source}

For the two fluorinated acids, PFHxA and PFOA, $\mathrm{pK}_{\mathrm{a}}$ was the most sensitive of the parameters studied $\left(\mathrm{pK}_{\mathrm{a}}, K_{\mathrm{ow}}\right.$, Sol 25, Pvap25 and KH25C). For PFOA, Goss (2008) estimates that the most correct $\mathrm{pK}_{\mathrm{a}}$ value is close to -0.5 , and this is the value that was used as original value in the calculations of the CF. Goss further describes the effects that the $\mathrm{pK}_{\mathrm{a}}$ value has for PFOA and other highly fluorinated carboxylic acids (e.g. PFHxA). PFOA would stay mostly in the air $(96 \%)$ if we assume a $\mathrm{pK}_{\mathrm{a}}$ value of 2.8 (Brace 1962), whereas it would reside almost completely in the water (99\%) if a $\mathrm{pK}_{\mathrm{a}}$ value of -0.5 (USEPA 2007) is assumed. In reality, $\mathrm{PFOA}$ is mostly found in the form of $\mathrm{PFO}^{-}$ions in water (Armitage 2009), and thus, a correct $\mathrm{pK}_{\mathrm{a}}(-0.5$ in the case of PFOA) is essential to achieve relevant modelling results for the fate of PFOA and other highly fluorinated carboxylic acids. For PFHxA, an experimental $\mathrm{pK}_{\mathrm{a}}$ value of 0.84 was available from one source only (Ding and Peijnenburg 2013); therefore, this parameter was not varied. The physicochemical data from literature for the other parameters ( $K_{\mathrm{ow}}$, Sol 25, Pvap 25 and $\mathrm{KH} 25 \mathrm{C}$ ) did not significantly change the CF for the fluorinated acids (Figs. S5 and S6, Electronic Supplementary Material). The EPI Suite database already contained experimental data for the $K_{\text {ow }}$ value for 4:2 FTOH and Pvap25 for PFOA. The literature was searched for experimental and estimated data for Sol 25, Pvap25 and KH25C - see Table S4 (Electronic Supplementary Material) for the results of this search. It can be noted that none of the investigated USEtox input parameter values varied two orders of magnitude (as they theoretically were in Sect. 3.3.1) between the experimental and/or estimated data available in literature.

The PFAS substance 4:2 FTOH is a neutral substance (not dissociating), and the parameter that varied most depending on data source was the Henry's law constant (how well gases dissolve in water). The $\mathrm{CF}$ for potential freshwater ecotoxicity from emissions to continental freshwater compartment for 4:2 FTOH may be underestimated with $35 \%$ if the EPI Suite-based input data is used. The other physicochemical parameters had insignificant impact for 4:2 FTOH. This analysis shows that for the PFAS, the $\mathrm{pK}_{\mathrm{a}}$ is a parameter that must be selected with extra care.

In addition to the PFAS CF sensitivity to the $\mathrm{pK}_{\mathrm{a}}$ value, the PFAS special partitioning behaviour may affect if the substances are correctly modelled. PFAS are often amphiphilic, i.e. with two parts of the molecule with different solution characteristics (Kissa 2001). In addition, a highly fluorinated molecule moiety is both hydrophobic and oleophobic (Kissa 2001), which make the octanol-water partitioning coefficient $\left(K_{\text {ow }}\right)$ an unsuitable measure of environmental fate. Other properties of the PFAS will be determining their fate, such as, e.g. organic carbon-water partitioning (Armitage et al. 2006) and protein binding affinity (Wang et al. 2016). Several of the parameters in the fate factor calculation of USEtox are based on $K_{\mathrm{ow}}$ (directly or indirectly), when EPIsuite estimation routines or USEtox internal routines are applied, and may not be correctly estimated for PFAS. The impact of this basis on the $\log K_{\text {ow }}$ on the PFAS CFs was not explored in the present study, and the PFAS CFs were flagged with a high uncertainty. One way forward to solve the problem of PFAS incompatibility with the traditional fate models is to enter data on the environmental partitioning such as the $\mathrm{K}_{\mathrm{OC}}$, rather than for the proxy $K_{\mathrm{ow}}$ (Armitage et al. 2006).

\subsection{Challenges and possible pitfalls}

Three general challenges in calculating CFs with the strategy proposed in the USEtox manual (and thus obtaining consistency with the pre-calculated USEtox $\mathrm{CFs}$ ) were identified and addressed in the strategy. Firstly, the USEtox manual for development of new CFs puts highest priority to WHO pesticide data sources (Huijbregts et al. 2015c). A large share of the substances that the two USEtox databases provide pre-calculated CFs for are also pesticides. The access to information about pesticides differs from the access to information about textile chemicals. For example, pesticides are regulated within the EU by the Biocidal Product Regulation (EC) No. 1107/2009 and in the USA by the Federal Insecticide, Fungicide and Rodenticide Act (FIFRA), which both imply that toxicological information must be presented before placing the pesticide product on the market. For textile chemicals in products, as well as many other types of chemicals in products, there are no such strict regulations, which limit toxicity data availability. Müller et al. (2017) explored the registration dossiers generated under the European REACH legislation as a data source for CFs. They found that REACH registration data can be used in USEtox but also highlight issues, such as differences in aim and scope between LCA and risk assessment methodology. Such issues were, e.g. that predominantly acute test data are available via REACH, which is in line with the (tonnage band-related) data requirements, as well as the focus on NOEC/NOEL in risk assessment, whilst USEtox uses $\mathrm{EC} / \mathrm{D}_{50}$ values. These issues were considered in the present work, and the REACH registration database is included amongst the databases in the data source selection strategy, including also estimated data contained therein.

Secondly, USEtox provides guidance for using experimental data for human toxicity, and the use of estimated data for ecotoxicological effects is only briefly mentioned, with no further guidance. However, many legal acts, for example REACH, aim to reduce animal testing. Estimated data will thus probably be increasingly important and frequent for chemicals used in the future. This is particularly likely since some hazardous and well-studied toxicants are being phased out and replaced with newer chemicals with less data available (Fantke et al. 2015). Considering this 
situation, inclusion of estimated data in a WoE approach was proposed as part of the data source selection strategy.

Thirdly, two of the recommended data sources are not publicly available: the ARChem SPARC calculator (Archem LCC 2016) and the RIVM e-toxBase (RIVM 2016). By suggesting alternative publicly available data sources, the data source selection strategy proposed here seeks to facilitate the calculation of new CFs for textile chemicals by a wider range of LCA practitioners. Addressing these three challenges, this paper proposes a data source selection strategy for the cases when the LCA practitioner needs to calculate CFs for non-pesticides, for substances where experimental data is not always available and without having to acquire expensive databases and/or software.

\subsubsection{Parameter specific challenges}

Table 5 summarises the parameter-specific challenges and possible pitfalls of data selection and how this is linked to uncertainty for different substance types. The summary is based on the discussion in this section and on the analysis of PFAS in Sect. 3.3.2. It should be noted that parameters that are uncertain for some substance types may have very low uncertainty for other substance types. For example, the degradation rate is not uncertain for extremely persistent chemicals, such as terminal degradation products of PFAS, which do not transform in the environment. On the other hand for substances for which degradation is largely dependent on the environmental conditions such as the presence of microorganisms or high acidity of water, the predictability of the degradation rate is low.

\section{Conclusions and recommendations}

This paper has discussed the guidelines for and uncertainties linked to data source selection for calculation of USEtox CFs. The paper has focused on LCA of textile products, and aimed to present a strategy for the situation where there is a need to calculate CFs for substances that are emitted during textile production. Textile products may also contribute to exposure of consumers during use, which can cause human toxicity impacts. The data source selection strategy for input to the USEtox model can also be used when applying the newly developed models describing this pathway (see Fantke et al. (2016)).

A data source selection strategy was developed and followed in order to ensure consistency and transparency when calculating CFs for 25 chemicals with USEtox 2.01. Toxicity data proved to be the most difficult data to obtain. At the same time, the sensitivity analysis showed that this is one of the most important input parameters in CF calculation. The low availability of experimental data is believed to remain or even increase in the future, with more restrictive animal testing (Swedish Chemicals Agency 2017). This means that guidance regarding which estimation methods are most suitable for certain substances (since most estimation methods and models have limitations in coverage) is important, and will be even more important in the future. For the proposed strategy in this paper, the selection of estimation methods was based on their applicability by LCA practitioners and documentation of scientific soundness. For the data set investigated in the study, the data estimation filled most of the data gaps, but in several cases, the resulting $\mathrm{CF}$ was categorised as non-MDQ. In the light of these results, further investigation of available toxicity data estimation methods applicable in LCIA may be worthwhile, as well as guidance to their use for an LCA practitioner. New development of additional methods may also be required if estimated data are to gain increased importance, also in an LCIA setting. In cases where MDQ CFs are needed, the recommendation to the LCA practitioner is to engage in interdisciplinary collaboration with experts in the field, until additional data estimation methods and/or further guidance to their use is available. Here, it is relevant to note that in a risk assessment setting, estimation of toxicity data is generally considered a time-saving procedure since the alternative, to carry through the experiment, would be both time consuming and costly (and require animal lives). In an LCA setting however, where the alternative to data estimation is often to accept a data gap, the data estimation can seem time consuming.

In this paper, it is shown that CF results depend on data source selection, and it thus provides rationale for a structured data source selection strategy where uncertainties are transparently communicated. The main uncertainty identified from developing CFs for textile chemicals was the selection of input data regarding toxicity and in some cases degradation rates, $\mathrm{pK}_{\mathrm{a}}$ and $K_{\mathrm{ow}}$. For persistent and amphiphilic substances, where PFAS have served as a textile-relevant example, properties such as $\mathrm{pK}_{\mathrm{a}}$ and $K_{\mathrm{ow}}$ are generally regarded as the most problematic properties in risk assessment (Armitage 2009). In USEtox however, these properties affect the CF less than the toxicity data.

The model uncertainty for USEtox is documented to be a factor of 100-1000 for human health and a factor of 10-100 for freshwater ecotoxicity. This uncertainty is recommended to be considered when interpreting the LCA results (Rosenbaum et al. 2008). Rosenbaum et al. (2008) state that inclusion of parameter uncertainty is desirable, and in the present study, focus has been put on parameter uncertainty, in particular related to the data selection. Within the data source selection strategy proposed herein, parameter uncertainty is qualitatively categorised according to the categories in Table 2. To quantitatively propagate those uncertainty estimations in further assessments where the CFs are applied, probability distributions could be applied with, e.g. Monte Carlo analysis (Grönholdt Palm et al. 2015).

We recommend LCA practitioners to include textile chemicals in LCA studies of textile products. We also hope that the new CFs provided and the developed data source selection 


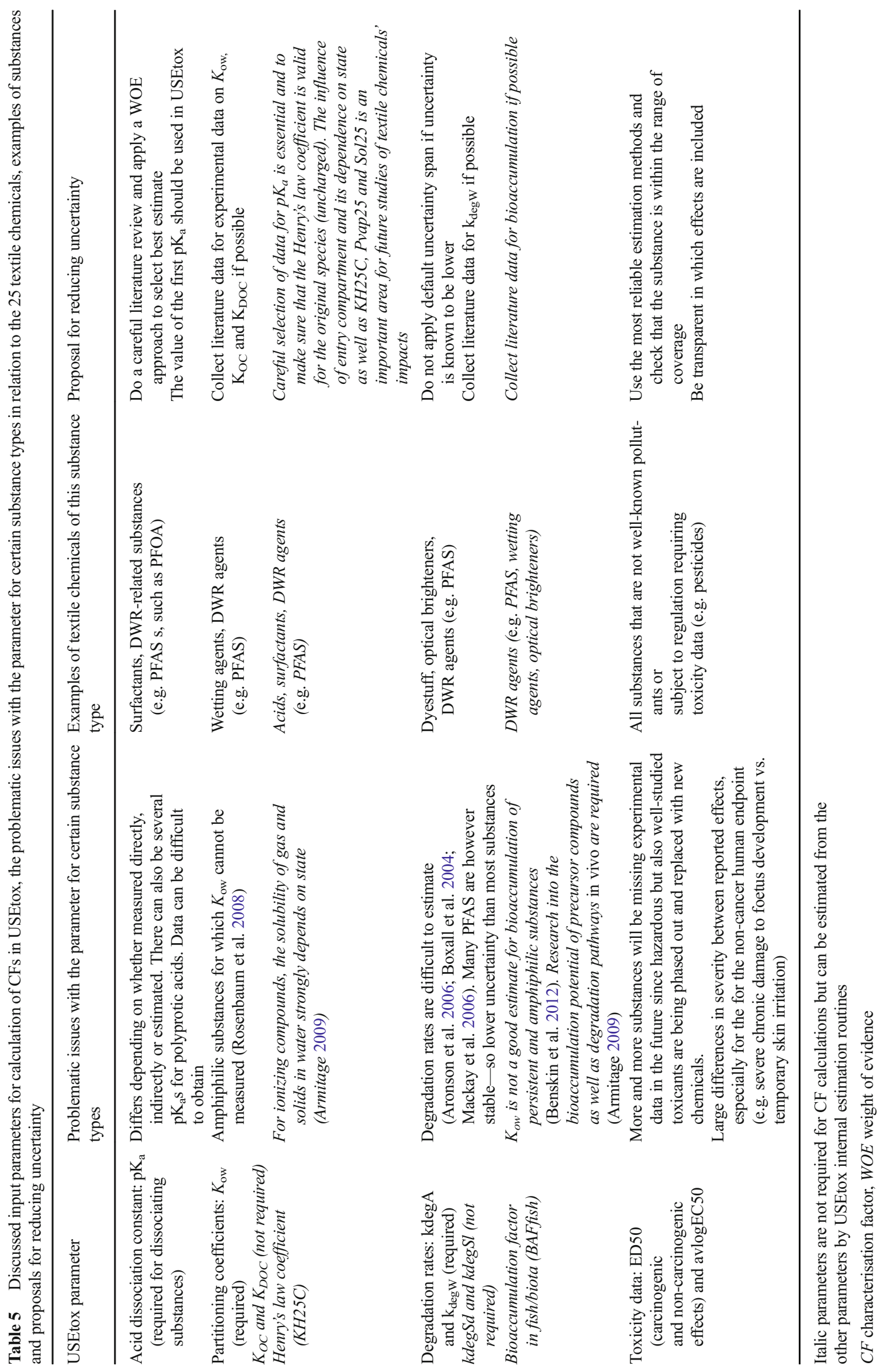


strategy can aid such inclusions. The proposed data source selection strategy offers transparency in the choice of data sources to encourage future studies to further improve the data quality and account for the causes behind uncertainties in the LCA.

Acknowledgements This research was supported by the Swedish Foundation for Strategic Environmental Research (Mistra) via the Mistra Future Fashion Programme and the Swedish Research Council for Environment, Agricultural Sciences and Spatial Planning (Formas) via the SUPFES project (grant agreement no. 2012-2148). We would also like to thank Associate Professor Patrik Andersson at Umeå University for the valuable advice regarding the data estimations.

Open Access This article is distributed under the terms of the Creative Commons Attribution 4.0 International License (http:// creativecommons.org/licenses/by/4.0/), which permits unrestricted use, distribution, and reproduction in any medium, provided you give appropriate credit to the original author(s) and the source, provide a link to the Creative Commons license, and indicate if changes were made.

\section{References}

ADEME (2015) USEtox COSMEDE [WWW document]. URL http:// usetox.tools4env.com/. Accessed 5.1.15

Alfonsín C, Hospido A, Omil F, Moreira MT, Feijoo G (2014) PPCPs in wastewater - update and calculation of characterization factors for their inclusion in LCA studies. J Clean Prod 83:245-255

Archem LCC (2016) ARChem SPARC calculator [WWW document]. URL http://archemcalc.com/sparc-web/calc. Accessed 6.8.16

Armitage JM (2009) Modeling the global fate and transport of perfluoroalkylated substances (PFAS). Stockholm University

Armitage JM, Cousins IT, Buck RC, Prevedouros K, Russell MH, Macleod M, Korzeniowski SH (2006) Modeling global-scale fate and transport of perfluorooctanoate emitted from direct sources. Environ Sci Technol 40:6969-6975

Aronson D, Boethling R, Howard P, Stiteler W (2006) Estimating biodegradation half-lives for use in chemical screening. Chemosphere 63(11):1953-1960. doi:10.1016/j.chemosphere.2005.09.044

Bare J (2012) Tool for the Reduction and Assessment of Chemical and other Environmental Impacts (TRACI): version 2.1 user's manual. EPA. United States Environ. Prot. Agency

Benskin JP, Muir DCG, Scott BF, Spencer C, Silva AOD, Kylin H et al (2012) Perfluoroalkyl acids in the Atlantic and Canadian Arctic oceans. Environ Sci Technol 46:5815-5823

Boxall ABA, Sinclair CJ, Fenner K, Kolpin D, Maund S (2004) When synthetic chemicals degrade in the environment. Environ Sci Technol 38(19):368A-375A

Brace NO (1962) Long chain alkanoic and alkenoic acids with perfluoroalkyl terminal segments. J Org Chem 27:4491-4498

Cronin M, Madden I (2010) In silico toxicology: principles and applications. Issues in Toxicology (Book 7), Royal Society of Chemistry

Dimitrov SD, Diderich R, Sobanski T, Pavlov TS, Chankov GV, Chapkanov AS, Karakolev YH, Temelkov SG, Vasilev RA, Gerova KD, Kuseva CD, Todorova ND, Mehmed AM, Rasenberg M, Mekenyan OG (2016) QSAR Toolbox-workflow and major functionalities. SAR QSAR Environ Res 27:203-219

Ding G, Peijnenburg WJGM (2013) Physicochemical properties and aquatic toxicity of poly- and perfluorinated compounds, critical reviews. Environ Sci Technol 43:598-678

ECHA (2008) Pre-registered substances [WWW document]. URL https://echa.europa.eu/information-on-chemicals/pre-registeredsubstances. Accessed 5.25.16
ECHA (2013) C\&L Inventory database. Retrieved from http://echa. europa.eu/web/guest/information-onchemicals/cl-inventorydatabase

ECHA (2014) Illustrative examples with the OECD QSAR Toolbox workflow. Helsinki, Finland

EFSA (2016) EFSA Open Food Tox. Retrieved June 25, 2016, from http://www.efsa.europa.eu/en/publications/efsajournal

European Commission (2003) Integrated Pollution Prevention and Control (IPPC) reference document on best available techniques for the textiles industry. European IPPC Bureau, Seville

European Commission (2006) Regulation (EC) No. 1907/2006 of the European Parliament and the Council of 18 December 2006 concerning the registration, evaluation, authorisation and restriction of chemicals (REACH), establishing a European chemicals agency, amending directive 1999/45/E. Off J Eur Union L396:0001-0851

European Commission (2010) International reference life cycle data system (ILCD) handbook - general guide for life cycle assessmentdetailed guidance, 1st ed. Publications Office of the European Union, Luxembourg. doi:10.2788/38479

European Commission (2011) International reference life cycle data system (ILCD) handbook - recommendations for life cycle impact assessment in the European context, 1st ed. EUR 24571 EN. Publications Office of the Europe, Luxemburg. doi:10.2788/33030

European Commission (2013) Commission recommendation of 9 April 2013 on the use of common methods to measure and communicate the life cycle environmental performance of products and organisations (2013/179/EU). Off. J. Eur. Union 56

Fantke P, Weber R, Scheringer M (2015) From incremental to fundamental substitution in chemical alternatives assessment. Sustain Chem Pharm 1:1-8

Fantke P, Ernstoff AS, Huang L, Csiszar SA, Jolliet O (2016) Coupled near-field and far-field exposure assessment framework for chemicals in consumer products. Environ Int 94:508-518

Goss K-U (2008) The $\mathrm{pK}_{\mathrm{a}}$ values of PFOA and other highly fluorinated carboxylic acids. Environ Sci Technol 42:456-458

Grönholdt Palm J, Rydberg T, Rahmberg M, Andersson H, Sahlin U (2015) A strategy to deal with information of differing quality exemplified by the use of QSARs to fill the algae data gap in an LCIA plastic, in: SETAC Europe 25th Annual Meeting. pp 4-5

Hauschild MZ, Jolliet O, Huijbregts MAJ (2011) A bright future for addressing chemical emissions in life cycle assessment. Int J Life Cycle Assess 16:697-700

Holmquist H, Schellenberger S, van der Veen I, Peters GM, Leonards PEG, Cousins I (2016) Properties, performance and associated hazards of state-of-the-art durable water repellent (DWR) chemistry for textile finishing. Environ Int 91:251-264

Huijbregts MAJ, Hauschild MZ, Margni M, Jolliet O, McKone TE, Van de Meent D, Rosenbaum RK (2015a) USEtox ${ }^{\circledR} 2.0$ manual: inorganic substances, 2nd ed. USEtox ${ }^{\circledR}$ Team, Lyngby, Denmark

Huijbregts MAJ, Margni M, Hauschild MZ, Jolliet O, McKone TE, Rosenbaum RK, Van De Meent D (2015b) USEtox® 2.0 user manual, 2nd ed. USEtox ${ }^{\circledR}$ Team, Lyngby, Denmark

Huijbregts MAJ, Van De Meent D, Margni M, Jolliet O, Rosenbaum RK, McKone TE, Hauschild MZ (2015c) USEtox ${ }^{\circledR} 2.0$ manual: organic substances, 2nd ed. USEtox® Team, Lyngby, Denmark

Igos E, Moeller R, Benetto E, Biwer A, Guiton M, Dieumegard P (2014) Development of USEtox characterisation factors for dishwasher detergents using data made available under REACH. Chemosphere 100:160-166

IUCLID (2007) IUCLID 5. Retrieved May 25, 2016, from http://www. iuclid.eu/index.php?fuseaction=home.project

Kissa E (2001) Fluorinated surfactants and repellents, 2nd edn. Marcel Decker, New York

Klimisch H-J, Andreae M, Tillmann U (1997) A systematic approach for evaluating the quality of experimental toxicological and ecotoxicological data. Regul Toxicol Pharmacol 25:1-5 
Larsen HF, Hansen MS, Hauschild MZ (2009) Life cycle assessment of offset printed matter with EDIP97: how important are emissions of chemicals? J Clean Prod 17:115-128

Laurent A, Olsen SI, Hauschild MZ (2012) Limitations of carbon footprint as indicator of environmental sustainability. Environ Sci Technol 46:4100-4108

Henan Surface Industry Co Ltd. (2016) New eco-friendly raw material sodium methyl ester sulphonate, MES 80/30 [WWW document]. URL http://surfaceindustry.lookchem.com/products/CasNo-9334822-2-New-ECO-Friendly-Raw-Material-Sodium-Methyl-EsterSulphonate-MES-80-30-12131156.html. Accessed 8.11.16

Maillard E, Hugonnot O, Roussel C (2013) International LCA Conference 2013, "USEtox COSMEDE footprinting": a web platform environmental footprinting of cosmetics and detergents for the 1-5

Mackay D, Shiu WY, Ma K, Lee SC (2006) Properties and Environmental Fate Second Edition Introduction and Hydrocarbons. Chemphyschem A European Journal Of Chemical Physics And Physical Chemistry (Vol. III). Retrieved from http:// www.crcnetbase.com/doi/book/10.1201/9781420044393

Müller N, de Zwart D, Hauschild M, Kijko G, Fantke P (2017) Exploring reach as potential data source for characterizing ecotoxicity in life cycle assessment. Environ Toxicol Chem 36:492-500

NLM (2005) TOXNET. Retrieved August 7, 2015, from https:/toxnet. nlm.nih.gov

NLM (2011) Hazardous Substances Data Bank (HSDB®). Retrieved February 17, 2016, from http://toxnet.nlm.nih.gov/newtoxnet/hsdb. $\mathrm{htm}$

OECD (2014) Guidance on grouping of chemicals, in: Series on Testing \& Assessment No. 194

OECD (2016a) QSAR Toolbox

OECD (2016b) eChemPortal [WWW document]. URL http://www. echemportal.org/. Accessed 5.25.16

OECD SIDS (2003) SIDS initial assessment report on hexadecanoic acid, 2sulfo, 1-methylester, sodium saltCAS No: 4016-24-4. Bern, Switzerland

Panko J, Hitchcock K (2011) Chemical footprint ensuring product sustainability. Air Waste Manag. Assoc.

Pennington DW, Potting J, Finnveden G, Lindeijer E, Jolliet O, Rydberg T, Rebitzer G (2004) Life cycle assessment part 2: current impact assessment practice. Environ Int 30:721-739

RIVM (2016) E-toxbase [WWW document]. URL http://www.ru.nl/ environmentalscience/research/themes-0/risk-assessment/etoxbase/. Accessed 6.23.16

Roos S (2015) Towards sustainable use of chemicals in the textile industry: how life cycle assessment can contribute. Chalmers University of Technology, Gothenburg

Roos S, Sandin G, Zamani B, Peters GM (2015) Environmental assessment of Swedish fashion consumption. Five garments - sustainable futures. Mistra Future Fashion, Stockholm
Rosenbaum RK, Bachmann TM, Gold LS, Huijbregts MAJ, Jolliet O, Juraske R, Koehler A, Larsen HF, MacLeod M, Margni M, McKone TE, Payet J, Schuhmacher M, Meent D, Hauschild MZ (2008) USEtox - the UNEP-SETAC toxicity model: recommended characterisation factors for human toxicity and freshwater ecotoxicity in life cycle impact assessment. Int J Life Cycle Assess 13:532-546

Rosenbaum RK, Huijbregts MAJ, Henderson AD, Margni M, McKone TE, Meent D, Hauschild MZ, Shaked S, Li DS, Gold LS, Jolliet O (2011) USEtox human exposure and toxicity factors for comparative assessment of toxic emissions in life cycle analysis: sensitivity to key chemical properties. Int J Life Cycle Assess 16:710-727

SDC \& AATCC (2016) Colour index [WWW document]. Soc. Dye. Colour. AATCC. URL http://www.colour-index.com/. Accessed 6.2.16

Swedish Chemicals Agency (2017) Kemikalieinspektionens strategi för myndighetens arbete med 3R-frågor. Report 1/17. Stockholm, Sweden

TEGEWA (2016) THK-online [WWW document]. URL http://www.thkonline.net/. Accessed 5.25.16

US EPA (1985) IRIS. Retrieved June 25, 2016, from https://www.epa. gov/iris

US EPA (2012) ECOSAR

US EPA (2017) T.E.S.T. [WWW document]

USEPA (2000) ECOTOX [WWW document]. URL http://www.epa.gov/ ecotox. Accessed 6.1.16

USEPA (2007) Estimation Programs Interface EPI Suite [WWW document]. URL http://www.epa.gov/oppt/exposure/pubs/episuitedl. $\mathrm{htm}$. Accessed 6.1.14

Wang Z, Macleod M, Cousins IT, Scheringer M, Hungerbühler K (2011) Using COSMOtherm to predict physicochemical properties of polyand perfluorinated alkyl substances (PFASs). Environ Chem 8:389398

Wang Z, Cousins IT, Hungerbühler K, Scheringer M (2016) Comparative assessment of the environmental hazards of and exposure to perfluoroalkyl phosphonic and phosphinic acids (PFPAs and PFPiAs): current knowledge, gaps, challenges and research needs. Environ Int 89-90:235-247

Weed DL (2005) Weight of evidence: a review of concept and methods. Risk Anal 25:1545-1557

Westh TB, Hauschild MZ, Birkved M, Jørgensen MS, Rosenbaum RK, Fantke P (2015) The USEtox story: a survey of model developer visions and user requirements. Int $\mathrm{J}$ Life Cycle Assess 20:299-310

Zhuravskii S, Yukina G, Kulikova O, Panevin A, Tomson V, Korolev D, Galagudza M (2016) Mast cell accumulation precedes tissue fibrosis induced by intravenously administered amorphous silica nanoparticles. Toxicol Mech Methods 26(4). doi:10.3109/15376516.2016. 1169341 